\title{
Implicações econômicas da taxação de exportações sobre agronegócio no Centro-Oeste brasileiro
}

\author{
Economic implications of the taxation of agribusiness exports in the Brazilian \\ Midwest
Implications économiques de la fiscalité des exportations sur le agribusiness Midwest brésilien

\section{Implicaciones económicas de la tasa de exportaciones sobre agronegocio en el Centro-Oeste brasileño}

\author{
Heverton Eustáquio Pinto ${ }^{1}$ \\ Sônia Milagres Teixeira ${ }^{1}$ \\ Marcelo Dias Paes Ferreira ${ }^{1}$
}

Recebido em 20/07/2017; revisado e aprovado em 04/10/2017; aceito em 01/11/2017

DOI: http://dx.doi.org/10.20435/inter.v19i3.1661

\begin{abstract}
Resumo: Em momentos de déficit orçamentário, os governos propõem aumentos de impostos para os setores mais dinâmicos. Essa foi uma política discutida para os estados do Centro-Oeste brasileiro diante da recente crise, em que foi proposto o aumento da taxação das exportações de grãos, oleaginosas e alimentos. Por meio de um modelo econômico de equilíbrio geral computável, foi verificado que tais políticas teriam um impacto negativo e, de forma concentrada, na região Centro-Oeste com perda de bem-estar, fluxo comercial e retração do Produto Interno Bruto $(P I B)$ da região. Os maiores impactos seriam verificados na produção de grãos e no setor de alimentos processados.
\end{abstract}

Palavras-chave: agregados econômicos; equilíbrio geral; grãos e alimentos processados.

Abstract: The government often proposes an increase tax toward a dynamic sector in an event of a budget deficit. This was the case for central west states governments in Brazil during the last crisis, wherein a tax raising on the exports of grains, oilseeds and processed food was considered. We assessed this scenario by a general equilibrium model and we found that the proposed tax raising would present a widespread negative effect in the mid-western economy related to a welfare, trade-flow and Gross Domestic Product (PIB). The greater impacts were seen in the grain, oilseeds and processed food sectors.

Keywords: economic aggregates; general equilibrium; processed food and grains.

Résumé: Le gouvernement propose souvent une augmentation de la taxe vers un secteur dynamique en cas de déficit budgétaire. Cela a été le cas pour les gouvernements des États du centre-ouest du Brésil durant la dernière crise, où une hausse des taxes sur les exportations de céréales, d'oléagineux et d'aliments transformés a été envisagée. Nous avons évalué ce scénario par un modèle d'équilibre général et nous avons constaté que la hausse des impôts proposée présenterait un effet négatif généralisé sur le bien-être, les flux commerciaux et le Produit Intérieur Brut (PIB) dans l'économie du centre-ouest. Les plus grands impacts ont été observés dans les secteurs des céréales, des oléagineux et des aliments transformés.

Mots-clés: agrégats économiques; equilibre général; céréales transformées et les aliments.

Resumen: El gobierno a menudo propone un aumento de impuestos hacia un sector dinámico en caso de déficit presupuestario. Este fue el caso de los gobiernos de los estados del medio oeste en Brasil durante la última crisis, donde se consideró una recaudación de impuestos sobre las exportaciones de granos, semillas oleaginosas y alimentos procesados. Evaluamos este escenario mediante un modelo de equilibrio general y encontramos que la recaudación de impuestos propuesta presentaría un efecto negativo generalizado en la economía del medio oeste relacionado con el bienestar, el flujo comercial y el Producto Interno Bruto (PIB). Los mayores impactos se observaron en los sectores de grano, semillas oleaginosas y alimentos procesados. Palabras clave: agregados económicos; equilibrio general; granos y alimentos procesados.

\footnotetext{
${ }^{1}$ Universidade Federal de Goiás, Goiânia, Goiás, Brasil.
} 


\section{INTRODUÇÃO}

O setor agrícola tem contribuído para o bem-estar econômico brasileiro, sendo um dos setores mais robustos da economia no presente momento de crise. No contexto de arrecadação declinante, a União e seus entes federados voltam a atenção ao setor agropecuário com vistas a aumentar a sua arrecadação. Nesse contexto, foi muito discutido, nos estados do Centro-Oeste brasileiro, um aumento na taxação de produtos primários, como grãos e oleaginosas. Apesar de ser uma opção interessante para o aumento da arrecadação, o aumento da tributação pode ter consequências indesejáveis para o formulador de políticas públicas. Por ser um setor estratégico para a região Centro-Oeste, o aumento da taxação poderá ter impactos negativos associados à perda de competitividade. A produção da cultura agrícola taxada poderá se deslocar para outras regiões do país e do mundo. Ademais, essa perda de produção poderá ter impactos em outros setores da economia da região, podendo ter consequências a montante e a jusante. Dessa forma, o presente estudo procura fomentar o debate sobre as prováveis medidas de taxação sobre a exportação de produtos primários por meio da aplicação de modelo de Equilíbrio Geral Computável (EGC).

Governos da região Centro-Oeste vêm se articulando para implementar taxações a produtos primários na região. Por exemplo, no estado de Goiás, tem-se o projeto lei anunciado, logo revogado, conhecido como a "lei 70/30", em que se constitui na lei 8.548, de 29 de janeiro de 2016. Tal lei estabeleceria mudanças no recolhimento de Imposto Sobre a Circulação de Mercadorias e Serviços (ICMS) nas operações de comercialização de soja e milho no estado, cabendo à Secretaria da Fazenda (SEFAZ-GO) estabelecer o volume da produção dos grãos em que incidirá o imposto sobre o excedente exportado. O principal argumento do governo estadual gira em torno da preocupação com o abastecimento dos produtos no estado, principalmente a disponibilidade de grão para o atendimento da demanda interna. Em Mato Grosso do Sul, já existe legislação similar desde 2005, estabelecida pelo decreto estadual 11.803 de fevereiro de 2005. O estado estabeleceu um regime especial de controle e fiscalização de exportação de soja e de milho, limitando 50\% da produção exportada e taxando-os, para quem ultrapassar o limite, em $12 \%$ de ICMS sobre as vendas externas. Contudo esse regime de lei é facultativo para os agentes que operam no estado e não foi aplicado na prática.

Diante desse cenário, o estudo visa discutir os efeitos de medidas da política comercial, a partir da taxação de exportações sobre bens primários, sobre parâmetros de competitividade e bem-estar social, a produção, o trânsito e os preços nos mercados regionais brasileiros. Este estudo se baseia na aplicação do GTAP (General Trade Analysis Project), projeto de análise do mercado global criado em 1992, que, em sua versão de 2011, engloba 140 regiões do mundo, incluindo o Brasil, e 57 bens/setores produtivos. Em conjunto com o pacote GTAP utilizou-se o pacote PAEG (Projeto de Análise de Equilíbrio Geral da Economia Brasileira)², que desmembra as cinco regiões brasileiras (TEIXEIRA; PEREIRA; GURGEL, 2013). Dessa forma, o presente trabalho capta as conexões regionais e internacionais da mudança da política pública.

Teoricamente, os efeitos de taxação sobre a agropecuária implicam perda de renda líquida para o setor, podendo comprometer as condições de competitividade e rentabilidade das suas

\footnotetext{
${ }^{2}$ O PAEG é um projeto desenvolvido junto ao Departamento de Economia Rural da Universidade Federal de Viçosa e conta com pesquisadores da Fundação Getúlio Vargas de São Paulo e da Universidade Federal do Mato Grosso do Sul. Maiores informações sobre esse projeto podem ser encontradas em: <http://www.novoscursos.ufv.br/projetos/ ufv/paeg/www/>.
} 
atividades, resultando em queda na produção e aumentos de preços até que seja reestabelecido um novo equilíbrio (REGAZZINI; BACHA, 2012). Dessa forma, o problema de pesquisa aqui abordado se concentra nos desdobramentos de uma taxação ad valorem sobre as exportações de grãos, oleaginosas e produtos alimentícios processados na região Centro-Oeste brasileira, assumindo que os três estados, Goiás, Mato Grosso e Mato Grosso do Sul, adotem uma alíquota de exportação dos bens acima supracitados.

Análises de políticas fiscais estão entre os objetos mais investigados na aplicação de metodologia de EGC. Alguns trabalhos aplicam EGC para mensurar impactos fiscais a partir de acordos comerciais (FIGUEREDO et al., 2010; BUENO; FEIJÓ, 2014; FEIJÓ; STEFFENS, 2015). Outros trabalhos tratam de impactos de reformas fiscais. Por exemplo, Sousa, Cardoso e Domingues (2016) simularam os impactos econômicos a partir da desoneração da folha de pagamentos. Esses autores apontaram que, no longo prazo, a redução na carga tributária gera efeitos positivos para o crescimento da economia, ocasionando o aumento no emprego de $0,27 \%$, acompanhado por uma elevação de 0,10\% no PIB e 0,25\% no consumo das famílias em relação ao cenário com ausência de desoneração. Pereira, Teixeira e Gurgel (2014) simularam um cenário onde ocorre a eliminação do ICMS, ISS e impostos indiretos federais como, IPI e CSCE, para a substituição de um Imposto sobre Valor Adicionado (IVA). Os principais efeitos encontrados pelos autores foram um aumento no fluxo comercial e melhora na distribuição de renda regional.

Análise empírica semelhante à proposta do presente estudo foi aplicada por Ponciano e Campos (2003). Os autores simularam um choque sobre o setor agropecuário brasileiro via eliminação de impostos sobre as exportações. Seus achados indicam aumento no nível de exportação e maior competição entre as atividades agroindustriais. Contudo, ao analisar os agregados econômicos, tais autores observaram queda do nível de bem-estar, embora tenha havido elevação do emprego rural e renda obtida no exterior.

O que distingue este dos outros trabalhos empíricos é a possibilidade de aplicar o choque em regiões e setores específicos, possibilitado pela última atualização e desagregação do PAEG (TEIXEIRA; PEREIRA; GURGEL, 2013). Ademais, este trabalho se insere em um contexto de política recentemente debatido no âmbito dos estados da região Centro-Oeste. Portanto o trabalho justifica-se em vista de fomentar o debate, iniciado em 2015, sobre os projetos de leis que governos estaduais da região têm discutido. Dessa forma, pretende-se atingir a proposta por meio de dois objetivos específicos. Primeiro, simular e discutir os efeitos da política de taxação a exportação de grãos no Centro-Oeste brasileiro; o recorte regional se deveu à limitação do modelo em termo de regionalização. Apesar de não haver nenhuma discussão de aumento de impostos de forma simultânea por parte dos estados da região Centro-Oeste, as simulações permitem verificar o potencial impacto de tais políticas. E segundo, discutir o potencial desdobramento para análise dos efeitos sobre a economia regional. A metodologia aplicada permite avaliar o impacto da mudança de política tributária não somente no setor e na região em que ocorreu a mudança, mas também o desdobramento em outras regiões e setores. Dessa maneira, acredita-se que a taxação de grãos e alimentos no Centro-Oeste venha a ter um efeito negativo na economia da região como um todo. Por serem setores dinâmicos, o deslocamento da produção de alimentos e grãos para outras regiões teria um impacto multissetorial, reduzindo a atividade econômica como um todo.

Além desta introdução, o trabalho segue com a apresentação da metodologia e o modelo na seção 2. Na seção 3, expõe a fonte de dados para o trabalho. Na seção 4, apresenta se a 
simulação e o choque proposto para as exportações de grãos, oleaginosas e alimentos industrializados. Na seção 5, encontram-se os resultados, em que são evidenciados os efeitos sobre os agregados econômicos e o fluxo comercial sobre as regiões brasileiras. E por fim, as conclusões a partir dos desdobramentos resultantes das simulações.

\section{METODOLOGIA}

A base metodológica deste trabalho é o modelo desenvolvido no PAEG. Tal modelo trata-se de um método quantitativo que utiliza estatísticas de contas nacionais (PIB setorial) recolhidas por organismos governamentais de diversos países, tais como o Instituto Brasileiro de Geografia e Estatística (IBGE) no Brasil, e consolidados em matrizes insumo-produto. Portanto tal método não apresenta caráter amostral, pois representa setores como um todo da economia. No contexto mais geral, o modelo contempla as dimensões globais, onde se ampliam com dados do comércio entre nações isoladas e em seus blocos econômicos, NAFTA (North American Free Trade Agreement) e CEE (Comunidade Econômica Europeia). Recentemente as regiões da Ásia foram incorporadas ao programa, o que permite a ampliação das avaliações de impactos, dada a estrutura do comércio global, com dados atualizados para 2011. Para o Brasil, foram utilizadas as matrizes Insumo-Produto de 2007 e 2008.

A construção de modelos de Equilíbrio Geral Computável (EGC) tem por finalidade captar as relações de interdependência entre as atividades setoriais e, por meio delas, examinar os efeitos diretos e indiretos decorrentes de choques exógenos resultantes de mudanças em medidas de políticas setoriais, macroeconômicas, comerciais e tecnológicas, entre outras, no ajustamento estrutural, na competitividade relativa das atividades e na distribuição dos benefícios dessas mudanças entre os agentes econômicos (RUTHERFORD, 1999). Os modelos de EGC retratam o funcionamento de uma economia através das relações matemáticas de comportamento dos agentes econômicos nos diversos mercados de bens, serviços e fatores de produção.

A base de dados para a construção de um modelo EGC é estruturada na forma de Matrizes de Contabilidade Social (MCS), que consistem em tabelas que registram todas as transações de uma economia em um determinado período de tempo. Os fluxos de renda e de bens de uma economia são representados de modo completo e consistente nas MCS, o que evidencia a interdependência existente entre as cadeias produtivas e os agentes envolvidos no funcionamento do sistema econômico (TEIXEIRA; PEREIRA; GURGEL, 2013).

O modelo compreende a produção e distribuição de bens e serviços na economia mundial. Cada região é representada através de uma estrutura de demanda final, onde se inclui a formação da renda das famílias e despesas privadas com bens e serviços, além de um agente público coletor de impostos e alocador de gastos para o provimento de serviços públicos. Assim, os setores produtivos buscam arranjar seus insumos intermediários e fatores primários de produção (capital, trabalho e recursos naturais), objetivando a minimização de seus custos, considerando-se a tecnologia utilizada nos processos produtivos. O banco de dados contém os fluxos bilaterais e multilaterais de comércio entre regiões e países, bem como os custos de transporte, tarifas de importação e impostos (ou subsídios) às exportações.

A otimização é definida através de uma função de produção caracterizada no modelo por uma função de elasticidade de substituição constante (CES), cujos componentes do valor adicionado (fatores primários de produção) podem ser substituídos, sendo tal processo determinado 
a partir de uma elasticidade de substituição. Já os insumos intermediários e o valor adicionado são otimizados a partir de uma função Leontief, em que não há possibilidade de substituição entre insumos. Por exemplo, capital e trabalho (fatores de produção) podem ser rearranjados no processo produtivo, mas não insumos de produção, como adubos, sementes etc. Ainda, cada j-ésimo insumo intermediário nessa função Leontief é um arranjo entre uma parcela doméstica e importada do mesmo bem j, combinadas a partir de uma função.

As relações levantadas anteriormente dizem respeito às identidades econômicas do modelo, contudo não descrevem o comportamento dos agentes econômicos. Para entender o funcionamento do modelo, é preciso descrever como os agentes e setores se comportam, a partir do comportamento baseados na teoria microeconômica. A Tabela 1 expõe as variáveis apresentando os níveis de atividades que definem um equilíbrio e as variáveis de preços relativos de bens e fatores. O modelo determina valores para todas as variáveis. As condições de equilíbrio do modelo são definidas a preços relativos, portanto não levam em consideração os preços nominais. Cada preço de equilíbrio está associado a uma condição de equilíbrio de mercado.

Tabela 1 - Variáveis endógenas no modelo representando níveis das atividades e preços de bens e fatores.

\begin{tabular}{ll}
\hline Variáveis & Descrição \\
\hline $\mathrm{C}_{r}$ & Demanda agregada dos agentes privados \\
$\mathrm{G}_{r}$ & Demanda agregada do setor público \\
$\mathrm{Y}_{\mathrm{ir}}$ & Produção \\
$\mathrm{M}_{\mathrm{ir}}$ & Importações agregadas \\
$\mathrm{FT}_{\mathrm{fr}}$ & Transformação de fatores \\
$\mathrm{YT}_{\mathrm{j}}$ & Serviços de transporte internacional \\
$\mathrm{PC}_{r}$ & Índice de preço do consumo privado \\
$\mathrm{PG}_{\mathrm{r}}$ & Índice de preço da provisão do governo \\
$\mathrm{PY}_{\mathrm{ir}}$ & Preço de oferta doméstica, bruto de impostos indiretos à produção \\
$\mathrm{PM}_{\mathrm{ir}}$ & Preço de importação, bruto de impostos às exportações e tarifas às importações \\
$\mathrm{PF}_{\mathrm{fr}}$ & Preço dos fatores para trabalho, terra e recursos naturais \\
$\mathrm{PF}_{\mathrm{F}}^{\mathrm{S}}$ & Preço dos fatores intermediários \\
$\mathrm{PT}_{\mathrm{j}}$ & Custo marginal dos serviços de transporte \\
\hline $\mathrm{F}_{\mathrm{j}}$ &
\end{tabular}

Fonte: Elaborado pelos autores.

Os setores produtivos buscam minimizar seus custos sujeitos às restrições/condições tecnológicas. A produção de $\mathrm{Y}_{\text {ir }}$ é caracterizada pela escolha de insumos a partir da minimização de custos unitários, representada pelo problema de otimização. Nessas equações, as variáveis de decisão correspondem aos dados iniciais (ou de "benchmark"), com a letra inicial "d" no lugar da letra " $v$ ". Dessa forma, vdfm ${ }_{\mathrm{jir}}$ representa a demanda intermediária de benchmark do bem j na produção do bem i na região $r$, enquanto ddfm $_{\text {jir }}$ representa a variável de demanda intermediária correspondente no equilíbrio do problema de decisão da produção.

A base de dados do GTAP possui dados para 140 regiões do mundo, incluindo o Brasil, e 57 bens/setores produtivos. Para a construção de um modelo de EGC, os setores e regiões são geralmente agregados em menor número, de acordo com os objetivos da pesquisa, de forma a aumentar a eficiência computacional das simulações e choques. No caso do presente trabalho, os dados do Brasil oriundos do GTAP foram substituídos pelos dados desagregados das regiões 
brasileiras (Norte, Nordeste, Sul, Sudeste e Centro-Oeste), contidos na MIP inter-regional. Os dados dos demais países são agregados em apenas uma ou poucas regiões: Resto do Mercosul, EUA, Resto do Nafta, Resto da América, Europa, China e Resto do Mundo.

\section{FONTE DOS DADOS}

A principal fonte de dados utilizada neste trabalho é a matriz inter-regional das macrorregiões brasileiras de 2011. Essa matriz foi obtida por uma atualização da matriz inter-regional brasileira elaborada por Parré (2000), que obteve a matriz Insumo-Produto brasileira, de 1995, desagregada para as cinco macrorregiões. A partir de então, atualizou-se a matriz para o ano de 2011, com base na evolução do Valor Adicionado Bruto das Grandes Regiões e Estados, por Atividade Econômica (IBGE, 2017). Em seguida, desagregou-se o setor agropecuário, que originalmente estava agregado em um único setor, tendo como base as matrizes insumo-produto de cada região, e, em seguida, foram obtidos os fluxos comerciais das regiões brasileiras com os outros países do modelo. Ao final desse processo, os dados foram compatibilizados à base de dados do GTAP 9.

\section{CENÁRIO ANALÍTICO E CHOQUE APLICADO NA SIMULAÇÃO}

O projeto de lei anunciado no estado de Goiás, mas não implementado, constitui-se na lei 8.548 , de 29 de janeiro de 2016. A normativa estabelece mudanças no recolhimento de ICMS nas operações de comercialização de soja e milho no estado, cabendo à Secretaria da Fazenda (SEFAZ-GO) estabelecer o volume da produção dos grãos que incidirá o imposto sobre o excedente exportado. Essa proporção seria estabelecida a cada exercício fiscal, em que, segundo a SEFAZ-GO, os parâmetros da proporção exportável e o valor do ICMS sobre as culturas objeto do decreto seriam estabelecidos de acordo com as condições de mercado julgada pelo secretário da Fazenda. O principal argumento do governo do estado revela preocupação com o abastecimento dos produtos no estado.

Pouco tempo após promulgação da lei, a SEFAZ-GO estabeleceu o que ficou conhecido como a lei "70/30", em que os produtores poderiam exportar livremente até $70 \%$ do volume de soja e milho negociados, os outros $30 \%$ restantes deveriam ser destinados ao mercado interno. Para as indústrias, haveria um limite de até $60 \%$ do volume para exportação, isento de ICMS, e $40 \%$ destinado ao mercado interno. Caso a regra fosse descumprida, a empresa deveria arcar com o Imposto sobre Circulação de Mercadorias e Serviços (ICMS) do montante excedente.

Em Mato Grosso do Sul, já existe legislação similar desde 2005, estabelecida pelo decreto estadual 11.803 de fevereiro de 2005. Foi criado um regime especial de controle e fiscalização de exportação de soja e de milho limitando $50 \%$ da produção exportada e taxando-os, para quem ultrapassar o limite, em $12 \%$ de ICMS sobre as vendas externas. Contudo esse regime de lei é facultativo para os agentes no estado. Essas leis vêm incentivando os governos dos estados do Centro-Oeste brasileiro e Tocantins a articularem taxações similares sobre a produção de bens primários, segundo a Sociedade Nacional de Agricultura (SNA, 2016).

A alíquota utilizada foi de $12 \%$ sobre o valor total exportado. O valor dessa alíquota é a mesma implantada em Mato Grosso do Sul e também utilizada na formulação da lei 8.548/16 pelo governo do estado de Goiás, até a sua revogação em agosto de 2016. A diferença entre as leis adotadas nos estados da região e o choque proposto no trabalho está na ausência de quotas 
exportações às quais está condicionada a alíquota estabelecida. Dessa forma, o trabalho simula os efeitos caso política similar possa ser estabelecida na principal região produtora do bem e serviço abordado na presente pesquisa. Apesar de não ser um cenário exatamente acoplado às políticas que têm sido discutidas para os estados do Centro-Oeste, é possível elucidar seus impactos qualitativos.

\section{RESULTADOS E DISCUSSÕES}

Nesta seção são expostos os impactos da política de aumento da taxação de exportação do agronegócio do Centro-Oeste, mediante uso de modelo EGC, sobre o nível de bem-estar econômico, o PIB agropecuário, o PIB de outros setores da economia, o retorno do capital e a massa salarial, composição do PIB e variação no nível de preços.

A Tabela 2 apresenta os resultados para indicadores de bem-estar ${ }^{3}$ e crescimento da economia para o cenário proposto. Caso haja aplicação de um imposto sobre exportação de grãos, oleaginosas e produtos alimentícios, seus efeitos serão concentrados e negativos na própria região Centro-Oeste. O modelo aponta uma perda de 2,9 bilhões de dólares em bem-estar, e uma queda de-2,74\% no PIB na região. Isso pode ser decorrente da grande importância econômica do setor agropecuário e sua integração com outros setores como indústrias e serviços na região. Há uma perda de bem-estar e de crescimento econômico no Brasil como um todo, porém não são expressivos quando comparados às regiões individuais. Maiores ganhos de bem-estar e crescimento relativo do PIB podem ser observados nas regiões Norte, Nordeste e Sudeste.

Tabela 2 - Variação do bem-estar e PIB para as regiões

\begin{tabular}{|c|c|c|c|c|}
\hline \multirow[b]{2}{*}{ REGIÕES } & \multicolumn{2}{|c|}{ Mudança no bem-estar } & \multicolumn{2}{|c|}{ Mudanças no PIB } \\
\hline & $\begin{array}{c}\text { Relativo } \\
(\%)\end{array}$ & 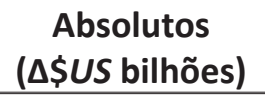 & $\begin{array}{c}\text { Relativo } \\
(\%)\end{array}$ & $\begin{array}{c}\text { Absolutos } \\
\text { ( } \Delta \$ \text { S bilhões) }\end{array}$ \\
\hline NORTE & 0,541 & 0,331 & 0,49 & 0,419 \\
\hline NORDESTE & 0,281 & 0,442 & 0,287 & 0,562 \\
\hline CENTRO-OESTE & $-2,901$ & $-2,863$ & $-2,738$ & $-3,682$ \\
\hline SUDESTE & 0,259 & 1,474 & 0,26 & 2,004 \\
\hline SUL & 0,232 & 0,485 & 0,218 & 0,693 \\
\hline RESTO MERCOSUL & 0,005 & 0,018 & N.D & $-0,003$ \\
\hline EUA & N.D & 0,029 & N.D & $-0,018$ \\
\hline RESTO NAFTA & N.D & 0,002 & N.D & $-0,010$ \\
\hline RESTO DA AMÉRICA & N.D & 0,001 & $-0,001$ & $-0,009$ \\
\hline EUROPA & $-0,001$ & $-0,053$ & $-0,001$ & $-0,139$ \\
\hline CHINA & $-0,007$ & $-0,088$ & $-0,002$ & $-0,054$ \\
\hline RESTO DO MUNDO & $-0,001$ & $-0,106$ & $-0,001$ & $-0,205$ \\
\hline
\end{tabular}

Fonte: Resultado da pesquisa

A Tabela 3 apresenta o desempenho econômico dos setores ligados à agropecuária por regiões em termos de variação no valor da produção. Resultados positivos denotam ganhos de

3 Os resultados em bem-estar são calculados a partir da variação equivalente hicksiana, que podem ser interpretados como mudanças no consumo das regiões a partir das alterações na renda e nos preços dos bens. Para mais detalhes ver Gurgel (2007) e Shoven e Whalley (1984). 
eficiência econômica (competitividade) em virtude da alteração de impostos. Os valores negativos indicam, para a maioria dos casos, que a produção passou a ser relativamente menos rentável (eficiente), deslocando recursos para outras atividades (PEREIRA; TEIXEIRA; GURGEL, 2014).

Tabela 3 - Variação no valor da produção para os setores ligados à agropecuária (\%)

\begin{tabular}{lccc|c|c|c|c|c|c}
\hline & Arroz & Grãos & $\begin{array}{c}\text { Sementes } \\
\text { Oleaginosas }\end{array}$ & $\begin{array}{c}\text { Cana-de- } \\
\text { Açúcar }\end{array}$ & $\begin{array}{c}\text { Prod. Origem } \\
\text { Animal }\end{array}$ & $\begin{array}{c}\text { Leite in } \\
\text { natura }\end{array}$ & $\begin{array}{c}\text { Outros } \\
\text { produtos } \\
\text { agrícolas }\end{array}$ & $\begin{array}{c}\text { Produtos } \\
\text { alimentares }\end{array}$ \\
\hline NORTE & 0,25 & 0,27 & 1,16 & 0,28 & 0,23 & 0,25 & 0,34 & 0,43 \\
NORDESTE & 0,34 & 0,31 & 1,41 & 0,28 & 0,24 & 0,31 & 0,32 & 0,33 \\
CENTRO-OESTE & $-1,38$ & $-2,93$ & $-16,25$ & $-2,06$ & $-1,91$ & $-1,77$ & $-1,29$ & $-6,12$ \\
SUDESTE & 0,21 & 0,23 & 1,35 & 0,21 & 0,21 & 0,24 & 0,26 & 0,27 \\
SUL & 0,14 & 0,21 & 0,55 & 0,19 & 0,18 & 0,18 & 0,23 & 0,25 \\
RESTO MERCOSUL & $-0,07$ & & 0,65 & 0,01 & 0,01 & 0,01 & $-0,05$ & 0,01 \\
EUA & 0,00 & 0,01 & 0,57 & 0,01 & 0,00 & 0,00 & 0,00 & 0,01 \\
RESTO NAFTA & 0,01 & 0,01 & 0,61 & 0,01 & 0,01 & 0,01 & 0,00 & 0,01 \\
RESTO DA AMÉRICA & 0,02 & 0,01 & 0,18 & 0,01 & 0,01 & 0,01 & 0,00 & 0,02 \\
EUROPA & 0,01 & 0,01 & 0,73 & 0,01 & 0,01 & 0,01 & 0,00 & 0,01 \\
CHINA & $-0,01$ & $-0,01$ & 0,48 & $-0,01$ & $-0,01$ & $-0,01$ & $-0,01$ & $-0,01$ \\
RESTO DO MUNDO & 0,01 & 0,00 & 0,19 & 0,01 & 0,01 & 0,00 & 0,00 & 0,01 \\
\hline
\end{tabular}

Fonte: Resultado de pesquisa.

Os resultados evidenciam uma perda sobre os valores da produção agropecuária na região Centro-Oeste após o choque da taxação às exportações de grãos. Todos os setores do Centro-Oeste brasileiro apresentaram valores negativos. A maior queda ocorre no setor de sementes oleaginosas $(-16,25 \%)$, seguido do processamento de alimentos $(-6,12 \%)$ e grãos $(-2,93 \%)$. Esse choque pode influenciar a produção de outras culturas na região devido à intensa coordenação da cadeia produtiva na região com a produção de grãos e alimentos processados. Observa-se uma queda na produção de cana-de-açúcar (-2,06\%), podendo ser um fenômeno atrelado à ausência de financiamento pela queda de receita no setor de grãos e taxação para a venda de açúcar para outros estados, pela queda produção de origem animal (-1,91\%) e bem como produção de leite in natura $(-1,71 \%)$. Neste último caso, pode haver um desencadeamento do aumento nos custos dos principais insumos do setor. As regiões Norte e Nordeste apresentam variação positiva em todos os setores ligados à agropecuária.

Nota-se um impacto quase nulo sobre os setores nas regiões externas, exceto para o setor de sementes e oleaginosas o qual reporta um crescimento positivo no valor de sua produção, na Europa (0,73\%), Resto do Mercosul (0,65\%), Resto do Nafta (0,61\%) e EUA (0,57\%). Estes, os concorrentes diretos do setor no comércio internacional, seriam os mais beneficiados com a aplicação do imposto sobre as exportações no Centro-Oeste brasileiro.

As quedas observadas na região Centro-Oeste e os ganhos em todas as demais regiões brasileiras podem ser explicadas pela hipótese da livre mobilidade de fatores, que deslocam fatores produtivos (capital e trabalho) para regiões que são relativamente mais beneficiadas com o aumento de imposto em um setor de relevância econômica para a economia nacional.

A Tabela 4 expõe as variações nos outros setores não agropecuários. Os efeitos da taxação sobre as exportações de grãos podem ser negativos para todos os setores não agropecuários do 
Centro-Oeste brasileiro. Esses resultados podem indicar que menores excedentes no setor de grãos provocados pela implantação de um imposto ad valorem nas exportações podem levar a uma queda nas divisas geradas pelo setor na região. Isso compromete a demanda em outras atividades econômicas da região, configurando em uma importante evidência da integração da produção de grãos no setor não agrícola da região e sua exposição ao mercado internacional.

Tabela 4 - Variação no valor da produção para os setores industriais e serviços (\%)

\begin{tabular}{|c|c|c|c|c|c|c|c|c|c|c|c|}
\hline & Têxteis & $\begin{array}{l}\text { Prod. de } \\
\text { vestuário } \\
\text { em couro }\end{array}$ & $\begin{array}{l}\text { Prod. } \\
\text { madeira }\end{array}$ & $\begin{array}{l}\text { Papéis e } \\
\text { celulose }\end{array}$ & $\begin{array}{c}\text { Prod. } \\
\text { quím. em } \\
\text { borracha e } \\
\text { plásticos }\end{array}$ & $\begin{array}{c}\text { Outras } \\
\text { manuf. }\end{array}$ & $\begin{array}{c}\text { Distrib. de } \\
\text { gás, água e e } \\
\text { eletricidade }\end{array}$ & $\begin{array}{c}\text { Constr. } \\
\text { civil }\end{array}$ & Comércio & Transp. & Serviços \\
\hline NORTE & 0.55 & 0.54 & 0.39 & 0.45 & 0.50 & 0.56 & 0.48 & 0.50 & 0.38 & 0.39 & 0.48 \\
\hline NORDESTE & 0.38 & 0.40 & 0.34 & 0.34 & 0.35 & 0.43 & 0.31 & 0.29 & 0.23 & 0.28 & 0.28 \\
\hline $\begin{array}{l}\text { CENTRO- } \\
\text { OESTE }\end{array}$ & -2.13 & -1.58 & -1.20 & -1.70 & -1.92 & -1.13 & -1.97 & -2.45 & -2.76 & -2.59 & -2.36 \\
\hline SUDESTE & 0.20 & 0.22 & 0.22 & 0.18 & 0.20 & 0.30 & 0.26 & 0.27 & 0.25 & 0.25 & 0.25 \\
\hline SUL & 0.21 & 0.25 & 0.22 & 0.15 & 0.20 & 0.24 & 0.24 & 0.24 & 0.22 & 0.22 & 0.17 \\
\hline $\begin{array}{c}\text { RESTO } \\
\text { MERCOSUL }\end{array}$ & -0.04 & -0.01 & -0.03 & -0.01 & -0.02 & -0.05 & -0.02 & & & -0.01 & 0.00 \\
\hline EUA & 0.00 & 0.00 & 0.00 & 0.00 & 0.00 & 0.00 & & & & 0.00 & \\
\hline $\begin{array}{l}\text { RESTO } \\
\text { NAFTA }\end{array}$ & & 0.00 & -0.01 & 0.00 & & -0.01 & 0.00 & & & & 0.00 \\
\hline $\begin{array}{l}\text { RESTODA } \\
\text { AMÉRICA }\end{array}$ & 0.00 & 0.00 & -0.01 & 0.00 & -0.01 & -0.01 & 0.00 & & 0.00 & 0.00 & 0.00 \\
\hline EUROPA & 0.00 & 0.00 & -0.01 & 0.00 & 0.00 & 0.00 & & & 0.00 & & 0.00 \\
\hline CHINA & -0.02 & -0.01 & 0.00 & 0.00 & 0.00 & & 0.00 & & 0.00 & & 0.00 \\
\hline $\begin{array}{c}\text { RESTODO } \\
\text { MUNDO }\end{array}$ & 0.00 & 0.00 & 0.00 & 0.00 & 0.00 & 0.00 & & & & 0.00 & 0.00 \\
\hline
\end{tabular}

Fonte: Resultado da pesquisa

Ao modelar o presente cenário empregando a livre mobilidade de fatores, é necessário ressaltar que, na prática, esse deslocamento de fatores não acontece livremente quanto ao que o modelo representa, portanto esse tipo de interpretação requer cautela. Assim, com a possibilidade de mobilidade dos fatores, sua alocação ocorrerá na direção em que ocorreria o comércio com base em vantagens comparativas. Em outras palavras, regiões relativamente abundantes em um fator produtivo são exportadoras potenciais de bens intensivos naquele fator e tenderão a movimentar-se para outras regiões (CARDOSO et al, 2014). Os resultados para a mobilidade dos fatores capital e trabalho (massa salarial) estão representados na figura 1, a qual expõe a mudança, em termos percentuais e reais, do retorno do capital e massa salarial pagos em cada região diante da taxação das exportações de grãos no Centro-Oeste brasileiro. 
Figura 1 - Variação percentual do retorno ao capital e massa salarial pagos nas regiões brasileiras em decorrência de uma implantação de um ICMS sobre a exportação de grãos no Centro-Oeste brasileiro

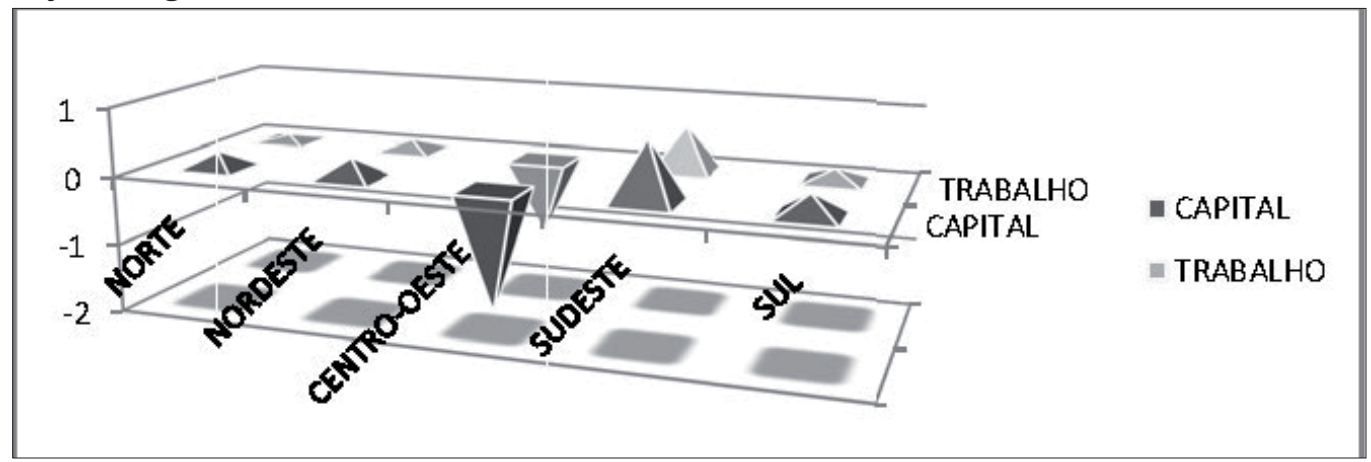

Fonte: Resultado da pesquisa.

De acordo com a figura 1, o Centro-Oeste é desfavorecido no contexto da taxação no que tange à renda ao capital e à massa salarial regional. A renda do capital cai 1,75\% enquanto a massa salarial se reduz em aproximadamente 1,1\%. Em contraposição, todas as demais regiões apresentaram aumento nos retornos dos fatores. Destaque para a região Sudeste que se apresenta como a maior beneficiária de uma possível taxação das exportações, com aumento de 0,87\% de aumento na renda do capital e 0,65\% na massa salarial. A intervenção pode provocar distorções na produção de bens e serviços. Ao taxar a exportação de bens primários da principal região produtora, isso provocará a mobilidade de fatores produtivos para região de maior atratividade econômica, nesse caso, o sudeste, e de maior concorrência comercial, nesse caso, a região sul.

Os efeitos do choque sobre os agregados macroeconômicos nas regiões e no Brasil podem ser observados na figura 2. Os resultados reforçam o efeito concentrado e negativo sobre a região Centro-Oeste. A maior retração ocorre no Consumo, seguido pelos Gastos do Governo na região. Ao contrário do que almejam os planejadores públicos, a taxação sobre a exportação de grãos pode retrair ainda mais a arrecadação.

Figura 2 - Composição da mudança no PIB segundo seus agregados para as regiões brasileiras e para o Brasil (em R\$ bilhões)

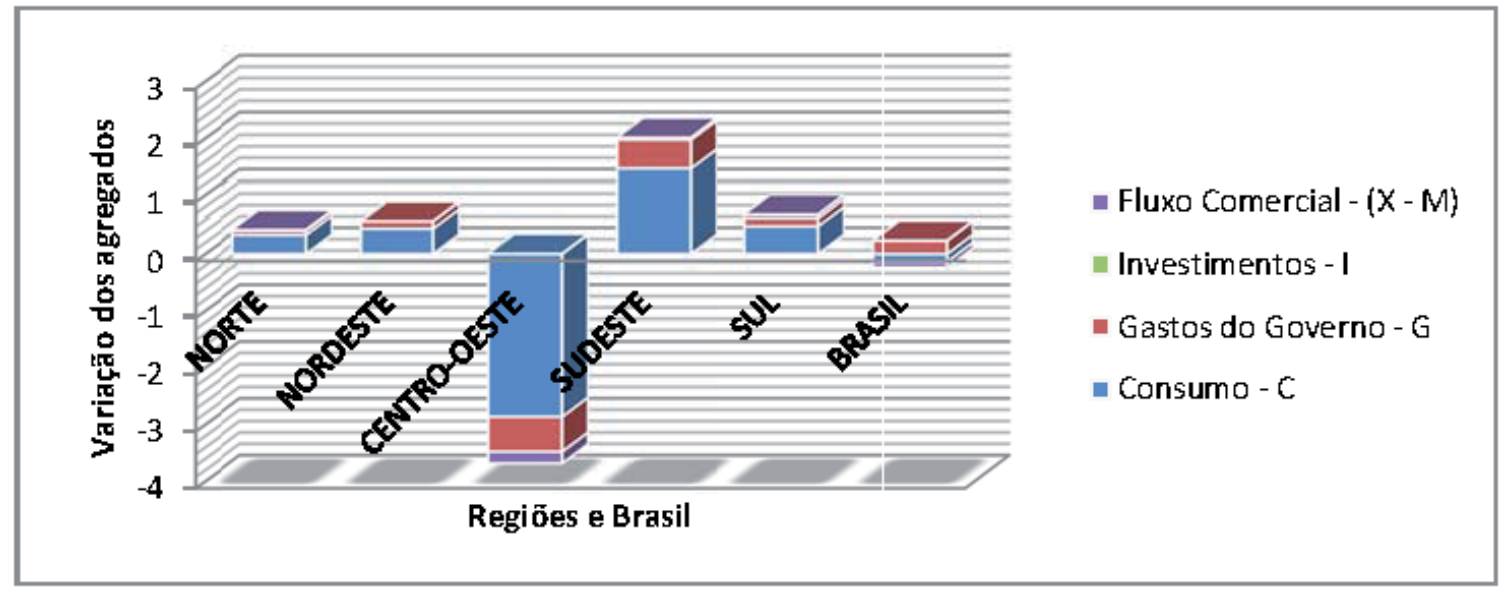

Fonte: Elaborada por autores. 
Em outras palavras, o resultado no crescimento na economia regional pode ser tão agressivo que os aumentos de impostos, principalmente em setores dinâmicos regionais, podem trazer efeitos não desejados aos formuladores de políticas públicas, podendo gerar até mesmo queda na arrecadação. Observa-se também uma queda no consumo das famílias, reforçando a relevância econômica do setor para a região. A redução nesses agregados pode estar associada à queda do fluxo comercial, o que pode gerar perda de divisas e perdas de excedentes promovidos pela implantação da taxa sobre exportação.

A Tabela 5 mostra a variação dos agregados por região e no Brasil, em termos absolutos. Analisando o fluxo comercial da região Centro-Oeste após o choque, verifica-se um distanciamento do comércio global evidenciado pela queda das exportações e importações. Contudo, nas regiões Sudeste e sul, verifica-se um aumento nas exportações. O valor das exportações nas regiões Sul e Sudeste em conjunto aumentam em 960,0 milhões de dólares, enquanto à perda em exportações identificada no Centro-Oeste somam 990,0 milhões de dólares.

Tabela 5 - Composição da mudança no PIB em termos absolutos segundo seus agregados para as regiões brasileiras e para o Brasil (em R\$ bilhões)

\begin{tabular}{lccccccc}
\hline Regiões / Agregados & Consumo & Gastos do Governo & Investimento & Exportação & Importação & \multicolumn{1}{c}{ PIB } \\
\hline NORTE & 0.33074 & 0.0741 & -0.00048 & 0.1502 & 0.13588 & 0.41868 \\
NORDESTE & 0.44197 & 0.12753 & -0.00013 & 0.14695 & 0.15402 & 0.5623 \\
CENTRO-OESTE & -2.86276 & -0.61329 & -0.0002 & -0.99171 & -0.78593 & -3.68203 \\
SUDESTE & 1.47186 & 0.50156 & -0.00264 & 0.65552 & 0.62174 & 2.00456 \\
SUL & 0.4842 & 0.14075 & -0.00051 & 0.30448 & 0.23574 & 0.69318 \\
\hline BRASIL & -0.134 & 0.2307 & -0.0039 & 0.2654 & 0.3615 & -0.004 \\
\hline
\end{tabular}

Fonte: Resultados da pesquisa

A Tabela 6 expõe o impacto da taxa de exportação sobre a variação dos preços das commodities. No setor de oleaginosas, verifica-se uma variação negativa para todas as regiões brasileiras. Exceto para a região Centro-Oeste, que reporta uma variação positiva no preço do grão $(1,3 \%)$, todas as regiões apresentam uma variação negativa para as culturas.

Tabela 6 - Variação de preços das commodities e produtos (\%)

\begin{tabular}{lrrrrc}
\hline Produtos & N & NE & CO & SE & S \\
\hline Arroz & 0,002 & $-0,016$ & & $-0,016$ & $-0,005$ \\
Grãos (cereais) & $-0,016$ & $-0,017$ & 0,013 & $-0,015$ & $-0,004$ \\
Sementes oleaginosas & $-0,005$ & $-0,018$ & $-0,006$ & $-0,017$ & $-0,005$ \\
Cana-de-açúcar & 0,005 & $-0,011$ & 0,012 & $-0,011$ & $-0,005$ \\
Prod. origem animal & $-0,009$ & $-0,011$ & $-0,003$ & $-0,016$ & $-0,003$ \\
Leite in natura & $-0,002$ & 0,013 & 0,002 & $-0,014$ & $-0,002$ \\
Outros prod. agrícola & $-0,005$ & $-0,007$ & 0,007 & $-0,015$ & $-0,004$ \\
Produtos alimentares & $-0,01$ & $-0,014$ & $-0,008$ & $-0,014$ & $-0,007$ \\
Têxteis & $-0,009$ & 0,005 & 0,001 & $-0,002$ & 0,002 \\
Vestuário e Couro & $-0,003$ & $-0,009$ & $-0,006$ & $-0,006$ & $-0,005$ \\
Madeira & $-0,001$ & 0,002 & $-0,005$ & $-0,009$ & $-0,004$ \\
Papeis e celulose & 0,007 & 0,014 & 0,006 & 0,002 & 0,004 \\
Quim. borrac. plást. & & 0,011 & 0,006 & 0,004 & 0,005 \\
\hline
\end{tabular}




\begin{tabular}{lrrrrr}
\hline Produtos & $\mathbf{N}$ & NE & CO & SE & \multicolumn{1}{c}{ S } \\
\hline Outras manufaturas & $-0,006$ & 0,01 & 0,005 & & 0,001 \\
Gás, água e eletr. & 0,009 & 0,006 & 0,004 & 0,001 & 0,002 \\
Construção civil & $-0,024$ & $-0,019$ & $-0,022$ & $-0,021$ & $-0,022$ \\
Comércio & 0,001 & 0,007 & $-0,004$ & $-0,005$ & $-0,003$ \\
Transportes & 0,015 & 0,005 & 0,002 & $-0,001$ & $-0,001$ \\
\hline Serviços & $-0,001$ & 0,001 & & 0,001 & 0,001 \\
\hline
\end{tabular}

Fonte: Resultados da pesquisa.

Esse comportamento pode ter como influência a taxação simulada na região Centro-Oeste, pois a barreira imposta ao mercado externo à maior região produtora das commodities produzidas, pode estimular as trocas internas entre as regiões, levando, assim, a um arrefecimento dos preços das commodities em questão, nas economias regionais próximas.

\section{CONCLUSÃO}

De forma geral, os principais resultados pontuais deste trabalho sugerem que um aumento de impostos estaduais sobre o agronegócio levaria a um impacto negativo e generalizado sobre a economia da região. Esse impacto negativo levaria a uma queda de arrecadação dos próprios estados, dado que o agronegócio é o setor mais dinâmico dessa região. Isso ocorre pelo fato de que a atividade agrícola se deslocaria para outras regiões brasileiras bem como para outros países, em vista do contexto de aumento de impostos. Nesse sentido, a decisão dos governos estaduais de não aumentar a alíquota desses setores foi acertada do ponto de vista tributário e econômico. Esses resultados estão em linha com a literatura, uma vez que tais efeitos são verificados em outros trabalhos. Trabalhos futuros poderiam focar em análises estaduais a fim de obter resultados mais específicos. Isso estaria mais acoplado à realidade, haja vista que a decisão de aumentos de impostos ocorre em nível estadual, não em nível macrorregional.

\section{REFERÊNCIAS}

BACHA, Carlos José Caetano. Economia e política agrícola no Brasil. São Paulo: Editora Atlas, 2012.

BUENO, Eduardo Urbanski; FEIJÓ, Flávio Tosi. A entrada da Venezuela no Mercosul: uma análise de equilíbrio geral computável sobre os impactos setoriais no Brasil. Pesquisa e Planejamento Econômico PPE, Brasília, v. 44, n. 1, abr. 2014.

CARDOSO, Débora Freire et al. Intervenção governamental, crescimento e bem-estar: efeitos da política de Equalização das Taxas de Juros do crédito rural nas regiões brasileiras. Nova Economia, Belo Horizonte, v. 24, n. 2, p. 363-88, 2014.

FEIJÓ, Flávio Tosi; STEFFENS, Camila. Comércio internacional, alocação do trabalho e a questão da desindustrialização no Brasil: uma abordagem utilizando equilíbrio geral computável. Revista de Economia Contemporânea, Rio de Janeiro, v. 19, n. 1, p. 135-61, jan./abr. 2015.

FIGUEIREDO, Adelson Martins; SANTOS, Maurinho Luiz; OLIVEIRA, Maria Aparecida Silva; CAMPOS, Antônio Ccarvalho. Impactos dos subsídios agrícolas dos Estados Unidos na expansão do agronegócio brasileiro. Estudos Econômicos, São Paulo, v. 40, n. 2, p. 445-67, abr./jun. 2010. 
GOIÁS, Estado. Secretaria de Estado da Casa Civil. Decreto n. 8.548/16, de 29 de janeiro de 2016. Altera o Regulamento do Código Tributário do Estado de Goiás no que diz respeito à substituição tributária nas operações com milho e soja. Suplemento do D.O. de 31/03/2016 e D.O. de 11/04/2016 - Errata. Disponível em: <http://www.gabinetecivil.goias.gov.br/decretos/ numerados/2016/decreto_8620.htm>.

GURGEL, Angelo Costa. Impactos da integração comercial sobre a agricultura familiar no Brasil. Repositório do Conhecimento do IPEA (RCIPEA). Pesquisa e Planejamento Econômico (PPE), Brasília, v. 37, n. 1, p. 21-74, abr. 2007. Disponível em: <http://ppe.ipea.gov.br/index.php/ppe/article/view/5/1000>.

GLOBAL TRADE ANALYSIS PROJECT (GTAP), 2001. Disponível em: <http://www.agecon. purdue.edu/gtap/>.

HERTEL, Thomas. W. (Ed.) Global trade analysis: modeling and applications. Cambridge; New York: Cambridge University Press, 1997.

MATO GROSSO DO SUL. Secretaria de Estado de Receita e Controle. Decreto n. 11.803, de 23 de fevereiro de 2005. Dispõe sobre o Regime Especial de Controle e Fiscalização relativo às operações de exportações e de saída para o fim específico de exportação, incluídas as remessas destinadas à formação de lote, e dá outras providências. Disponível em: <http://www.legiscenter.com.br/minha_conta/bj_plus/direito_tributario/ atos_legais_estaduais/mato_grosso_do_sul/decretos/2005/decreto_11803_de_24-02-05.htm>.

INSTITUTO BRASILEIRO DE GEOGRAFIA E ESTATÍSTICA (IBGE). Estatística. [s.d.]. Disponível em: <http:// www.ibge.gov.br/home/download/estatistica.shtm>. Acesso em: 10 jan. 2017.

PARRÉ, José Luiz. O agronegócio nas macrorregiões brasileiras: 1985 a 1995. 2000. 191f. Tese (Doutorado em Economia Aplicada) - Escola Superior de Agricultura Luiz de Queiroz, Piracicaba, SP, 2000.

PEREIRA, Matheus Wemerson Gomes; TEIXEIRA, Erly Cardoso; GURGEL, Ângelo Costa. Uma análise da reforma tributária sobre a economia e a competitividade setorial das macrorregiões brasileiras. Revista de Economia, Curitiba, v. 40, n. 3, 2014.

PONCIANO, Niraldo José; CAMPOS, Antônio Carvalho. Eliminação dos impostos sobre as exportações do agronegócio e seus efeitos no comportamento da economia. Revista Brasileira de Economia, v. 57, n. 3, p. 637-58, 2003.

REGAZZINI, Leonardo Coviello; BACHA, Carlos José Caetano. Tributação e gastos federais na agropecuária brasileira. Revista de Política Agrícola, Brasília, v. 21, n. 3, p. 55-67, jul./set. 2012.

RUTHERFORD, Thomas F. Applied general equilibrium modeling with MPSGE as a GAMS subsystem: an overview of the modeling framework and syntax. Computational Economics, v. 14, n. 1-2, p. 1-46, out. 1999.

SOCIEDADE NACIONAL DE AGRICULTURA (SNA). Intenção de 3 estados de cobrar ICMS sobre exportação de soja e milho gera polêmica. nov. 2015. Disponível em: <http://sna.agr.br/intencao-de-3-estados-decobrar-icms-sobre-exportacao-de-soja-e-milho-gera-polemica/>. Acesso em: 10 dez. 2016.

SOUZA, Kênia Barreiro de; CARDOSO, Débora Freire; DOMINGUES, Edson Paulo. Medidas recentes de desoneração tributária no Brasil: uma análise de equilíbrio geral computável. Revista Brasileira de Economia, Rio de Janeiro, v. 70, n. 1, p. 99-125, 2016.

SHOVEN, John B.; WHALLEY, John. Applied general-equilibrium models of taxation and international trade: an introduction and survey. Journal of Economic Literature, v. 22, n. 3, p. 1007-51, 1984.

TEIXEIRA, Erly Cardoso; PEREIRA, Matheus Wemerson; GURGEL, Ângelo Costa (Org.). A estrutura PAEG. 1. ed. Campo Grande, MS: Editora Life, 2013. 


\section{Sobre autores:}

Heverton Eustáquio Pinto: Mestrado em Agronegócios. Graduação em Ciências Econômicas. Pesquisador e estagiário no Centro de Pesquisas Econômicas e Mercadológicas (CEPEM-ALFA). Sócio Proprietário da HEX Indústria, Comércio e Distribuição de Artigos do Vestuário. E-mail: heverton.mg@uol.com.br

Sônia Milagres Teixeira: Doutorado em Economia Rural pela Purdue University. Mestrado em Economia Rural pela University of Wisconsin - Milwaukee. Graduação em Matemática (Bacharelado e Licenciatura) pela Universidade Federal de Visçosa. Professora Titular na Escola de Agronomia da Universidade Federal de Goiás. E-mail: soniamilagresteixeira@gmail.com

Marcelo Dias Paes Ferreira: Mestrado e doutorado em Economia Aplicada, e graduação em Gestão do Agronegócio pela Universidade Federal de Viçosa. Professor na Escola de Agronomia da Universidade Federal de Goiás, atuando no Programa de Pós-Graduação em Agronegócio.

E-mail: marcelo.ferreira@ufg.br 